\title{
Bax gene G(-248)A promoter polymorphism is associated with increased lifespan of the neutrophils of patients with osteomyelitis
}

Marcos G. Ocaña, $P h D^{1}$ Eulalia Valle-Garay, $P h D^{1}$ A. Hugo Montes, $P h D^{1}$, Álvaro Meana, MD, $P h D^{1}$ José Antonio Cartón, $\mathrm{MD}, \mathrm{Ph} \mathrm{D}^{1}$, Joshua Fierer, $M \mathrm{D}^{2}$, Antonio Celada, $\mathrm{MD}, \mathrm{Ph} \mathrm{D}^{3}$, and Víctor Asensi, $\mathrm{PhD}, \mathrm{MD}^{1}$

\begin{abstract}
Background: Patients with osteomyelitis have a decreased rate of spontaneous apoptosis of their peripheral blood neutrophils. The G(-248)A polymorphism in the promoter region of the bax gene is associated with prolonged peripheral blood neutrophil survival in leukemic patients and may play some role in osteomyelitis. Methods: Bax G(-248)A promoter polymorphism was detected by DNA amplification using polymerase chain reaction, followed by restriction fragment length polymorphism analysis. Spontaneous apoptosis of peripheral blood neutrophils was measured by propidium iodide, annexin $\mathrm{V}$, and flow cytometry, and Bax was quantified by Western blotting. Results: The bax promoter polymorphism A allele was significantly more frequent in 80 patients with osteomyelitis than in 220 healthy donors $\left(18.1 \%\right.$ vs. $10.6 \%, \chi^{2}=4.84$, odds ratio $=1.81,95 \%$ confidence interval $=1.06-3.07, P=$ .028). Carriers of the A allele had a lower apoptotic rate of their peripheral blood neutrophils compared with noncarriers $(33.3 \pm 16.7$ vs. $43.1 \pm 3.1, P=.036)$. Patients with the AA genotype showed a lower expression of the Bax protein compared with carriers of other genotypes $(P=.038)$. Conclusions: Substitution of a nucleotide $\mathrm{G} \rightarrow \mathrm{A}$ at position -248 in the bax gene was more frequent in patients with osteomyelitis and was associated with a longer lifespan of their peripheral blood neutrophils and lower Bax protein expression. These findings may play a role in the pathogenesis of osteomyelitis. Genet Med 2007:9(4):249-255.
\end{abstract}

Key Words: bax, polymorphism, osteomyelitis, neutrophils, apoptosis

Osteomyelitis (OM) is a difficult-to-treat bone infection characterized by progressive inflammatory destruction of the bone, bone necrosis, and new bone formation. In adults, OM usually is a complication of open wounds involving the bone, from fractures, surgery, or both. The risk and severity of infection can be enhanced by the presence of a foreign body (metallic or prosthetic devices). It is reported that $0.4 \%$ to $7 \%$ of trauma and orthopedic operations are complicated by OM. This infection can also develop in a noninjured bone after bacteremia, mostly in prepubertal children and elderly patients, when the infection involves the axial skeleton. Staphylococcus aureus is the microorganism most frequently isolated in both posttraumatic and hematogenous OM. Despite appropriate combined medical and surgical therapies, up to $30 \%$ of OM becomes chronic, causing major economic losses and personal morbidity and

\footnotetext{
From the ${ }^{1}$ Biochemistry and Molecular Biology Department and Infectious Diseases Services, Oviedo University Medical School and Hospital Central de Asturias, Oviedo, Spain; ${ }^{2}$ Infectious Diseases Section, VAMC and University of California, San Diego, California; and ${ }^{3}$ Biomedical Research Institute of Barcelona-Scientific Park, University of Barcelona, Spain. Victor Asensi, PhD, MD, Infectious Diseases Unit, Hospital Central de Asturias, Oviedo University Medical School, C/Celestino Villamil s/n, 33006 Oviedo, Spain. E-mail: vasensia@medynet.com
}

The authors declare no conflict of interest.

Submitted for publication October 4, 2006.

Accepted for publication January 12, 2007.

DOI: 10.1097/GIM.0b013e318039b23d mortality. ${ }^{1}$ Much attention has been dedicated to improving the surgical and medical treatment of $\mathrm{OM}$, but little progress has been made toward understanding its pathogenesis. It is clear that OM is multifactorial and mainly influenced by local factors related to the bone lesion and microorganisms inoculated into the bone, but inherited factors and cell immunity dysfunctions may play some role. ${ }^{2-4}$

Polymorphonuclear neutrophils are potent phagocytes that are the first line of the host immune defense against many infections. Clearance of neutrophils through apoptosis and their subsequent ingestion by macrophages play an important role in limiting the destructive potential of neutrophils leading to resolution of the inflammation..$^{5-7}$

Neutrophil apoptosis is controlled by down- or up-regulation of the Bcl-2 family proteins, which may include the antiapoptotic proteins $\mathrm{Mcl}-1, \mathrm{Al}$, and $\mathrm{Bcl}-\mathrm{X}_{1}$, and the proapoptotic proteins Bax- $\alpha$, Bid, Bak, and Bad. ${ }^{8-13}$ The ratio of antiapoptotic to proapoptotic proteins is critical to regulate cell apoptosis. A high Bcl2/Bax ratio and higher levels of Mcl-1 were strongly correlated with prolonged leukemic cell survival. ${ }^{14,15}$ Mutations in the promoter and coding regions of the bax gene affected protein expression and function. ${ }^{16,17}$ Recently, a novel single nucleotide polymorphism (SNP), G(-248)A, in the $5^{\prime}$ - untranslated region of the bax gene was found in patients with chronic lymphocytic leukemia, a malignancy characterized by accumulation of lymphocytes resulting from failed apoptosis. ${ }^{18,19}$ Delayed neutrophil apoptosis 
is also associated with various proinflammatory diseases, including systemic inflammatory response syndrome, ischemia-reperfusion injury, and adult respiratory distress syndrome. ${ }^{20-23} \mathrm{In}-$ creased levels of inflammatory cytokines have been reported in serum and surgically obtained bone fragments of humans $s^{24,25}$ and mice with OM. ${ }^{26,27}$ Some of the cytokines and growth factors, such as interleukin (IL)- $1 \beta$, IL-2, IL-15, interferon- $\gamma$, granulocyte colony-stimulating factor, and granulocyte-macrophage colonystimulating factor, are reported to inhibit in vitro neutrophil apoptosis. ${ }^{28-30}$ Others (e.g., tumor necrosis factor- $\alpha$ ) induce or delay neutrophil apoptosis, ${ }^{24,31,32}$ and the effect of IL-6 is variable as well. ${ }^{33-38}$

Our group recently showed that the apoptosis of peripheral neutrophils from patients with OM was decreased in relation to healthy controls and that this effect seemed to be the result, at least in part, of the high levels of circulating IL-6. ${ }^{39}$ In the present work we tried to determine whether the bax $\mathrm{G}(-248) \mathrm{A}$ promoter polymorphism (rs 4645878) could play a similar role in reducing apoptosis of neutrophils from patients with $\mathrm{OM}$, perhaps leading to impaired resolution of the bone infection.

\section{PATIENTS AND METHODS}

\section{Patients}

Eighty patients ( 53 men and 27 women, with a mean age of $55.5 \pm 17.7$ years, range $16-89$ years) who were admitted between January 1998 and June 2006 to the Hospital Central de Asturias, Oviedo, and to three other affiliated hospitals of the same northern Spanish region were studied. Patients with acute ( 55 cases) and chronic ( 25 cases) OM were included in the study and followed for 1 year. OM was diagnosed by clinical, roentgenographic, tomographic, and isotopic bone imaging criteria. Surgical and sinus tract pus samples were cultured in all the patients with OM. OM was considered chronic if it was present for more than 3 months and cured if did not relapse during 1 year of follow-up. In addition, 220 Blood Bank donors, matched for age and sex with the patients, were used as controls. Each participant gave informed consent for the study, which was approved by the ethics committee of the Hospital Central de Asturias.

\section{Human neutrophil isolation}

Ten milliliters of peripheral blood were collected for each assay from patients with OM or healthy individuals and deposited in Vacutainer plastic tubes containing potassium-EDTA (Vacuette, Greiner Bio-One, Kremsmuenster, Austria). Neutrophils were purified by Ficoll-Hypaque (Lymphoprep, Axis-Shield Poc AS, Oslo, Norway) centrifugation as previously described..$^{39}$ Cells collected from the gradient interface contained more than $95 \%$ neutrophils by Coulter identification and were more than $95 \%$ viable by trypan blue exclusion. Neutrophils were isolated before each experiment and used immediately.

\section{Culture conditions}

Culture conditions involved incubating $5 \times 10^{6}$ neutrophils with $200 \mu \mathrm{L}$ of Ham's F-12 medium (Gibco, Paisley, Scotland, UK) at $37^{\circ} \mathrm{C}$ for 12 hours, and apoptosis was then measured.

\section{Flow cytometry}

Cell death of neutrophils was measured by propidium iodide (PI) staining as described by others. ${ }^{40}$ The PI fluorescence of individual cells was measured with a flow cytometer (Cytomics FC500, Beckman-Coulter Inc., Miami, FL). Mean fluorescence values were determined from a minimum of $1 \times 10^{4}$ cells within an analysis region corresponding to nonfragmented neutrophils using Cytomics RXP Software (BeckmanCoulter Inc.) for data acquisition analysis. In some additional experiments, neutrophil apoptosis was measured by the annexin V-FITC Apoptosis Detection Kit (Sigma, St. Louis, MO) according to the protocol provided by the company.

\section{Amplification of the bax promoter region}

We collected $10 \mathrm{~mL}$ of blood from each patient and control individuals in tubes containing potassium-EDTA. Genomic DNA was extracted from peripheral leukocytes using a salting-out method. ${ }^{41}$ To determine the bax genotype of the samples, the genomic DNA was amplified with primers (forward primer: 5' -CGGGGTTATCTCTTGGGC-3'; reverse primer, $5^{\prime}$-GTGAGAGCCCCGCTGAAC-3' $) .{ }^{42}$ The polymerase chain reaction (PCR) was performed in a final volume of 16 $\mu \mathrm{L}$, containing $100 \mathrm{ng}$ of genomic DNA, and consisting of an initial denaturation at $95^{\circ} \mathrm{C}$ for 5 minutes; followed by $40 \mathrm{cy}$ cles of 30 seconds at $94^{\circ} \mathrm{C}, 30$ seconds at $56^{\circ} \mathrm{C}$, and 45 seconds $72^{\circ} \mathrm{C}$; and a final extension of 5 minutes at $72^{\circ} \mathrm{C}$.

\section{Restriction enzyme analysis}

The restriction enzyme Aci I (New England BioLabs Inc., Beverly, MA) was used to screen the samples for the SNP detection following the protocol of Moshynska et al. ${ }^{19}$ Essentially, the PCR products were incubated for 3 hours at $37^{\circ} \mathrm{C}$ with the restriction enzyme Aci I. Aliquots of $10 \mu \mathrm{L}$ of the digested PCR products were then electrophoresed on a $7.5 \%$ polyacrylamide gel at $165 \mathrm{~V}$ for 80 minutes in an electrophoresis apparatus (Mini-Protean II, Bio-Rad, Hercules, CA). PCR products were visualized after staining with ethidium bromide (Sigma, St. Louis, MO). Homozygous GG (wild-type) were visualized as three major bands of 352, 256, and 96 base pair (bp) (GG). It should be noted that the 256-bp band was the most intense. Heterozygous AG resulted in the loss of a restriction site for Aci I in one of the bax promoters and showed three bands, with the 352-bp band being the most intense, whereas the 96-bp band became almost invisible. Homozygous AA (homozygous carrier of the SNP) showed only the 352-bp band (Fig. 1).

\section{Sequence analysis}

The results of the restriction analysis were confirmed by sequence analysis of representative samples for each genotype (Fig. 1). PCR products were purified using spin columns (High Pure PCR Product Purification Kit, Roche, Mannheim, Germany) and sequenced on an ABI Prism 3100 Genetic Analyser (Applied Biosystems, Foster City, CA), according to the manufacturer's instructions. The sequences were compared with bax data in the GenBank (accession number U17193 for promoter). 


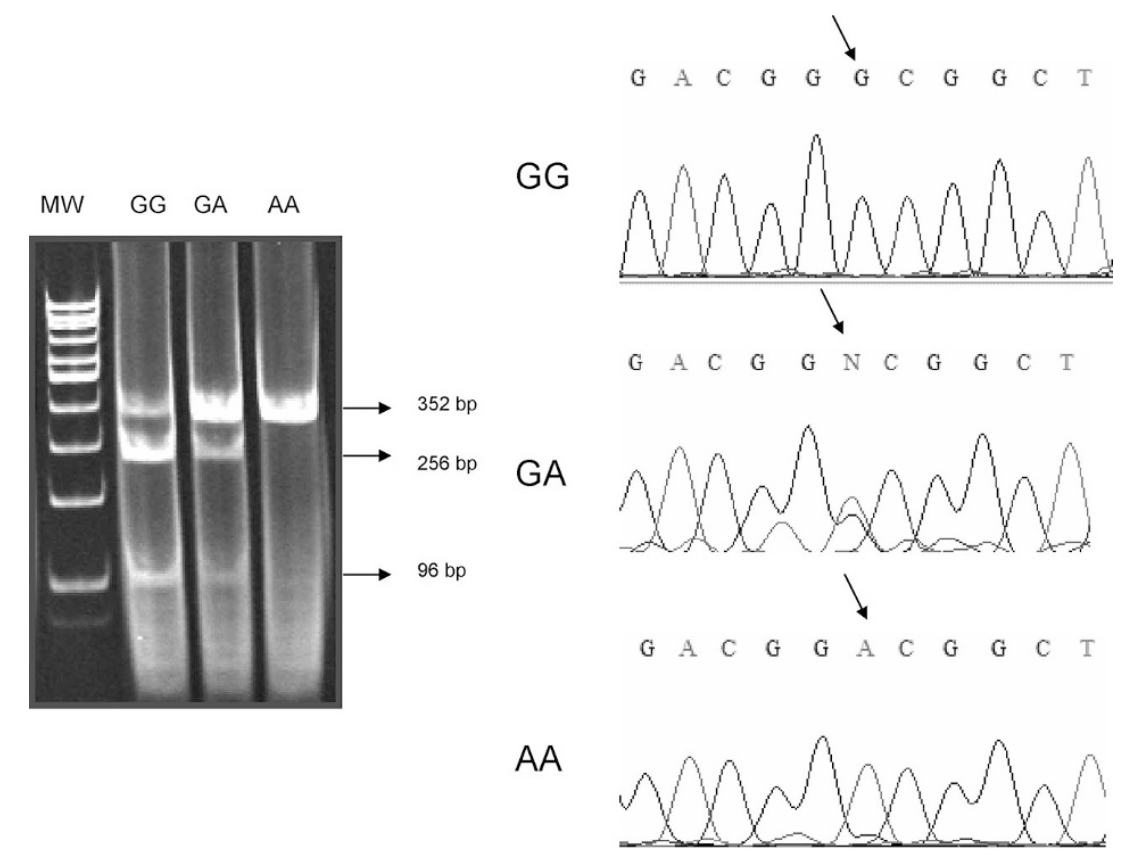

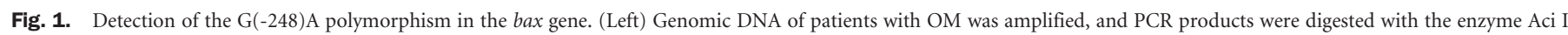

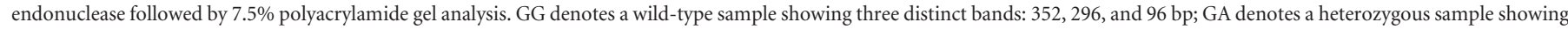

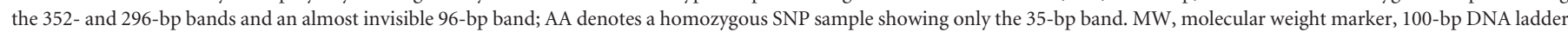

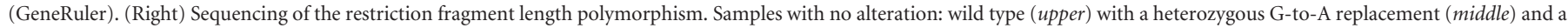
homozygous AA genotype (lower).

\section{Protein purification and Western blotting}

Then, $5 \times 10^{6}$ neutrophils were collected and washed in phosphate-buffered saline. They were resuspended in a lysis buffer ( $50 \mathrm{mM}$ Tris- $\mathrm{HCl}, 150 \mathrm{mM} \mathrm{NaCl}, 1 \%$ Triton-X, $2 \mathrm{mM}$ EDTA, 8 mM EGTA, $0.5 \mathrm{mM}$ AEBSF), incubated for $30 \mathrm{~min}$ utes on ice, and centrifuged at $16,000 \mathrm{~g}$ at $4^{\circ} \mathrm{C}$. Protein concentration was measured from the supernatant using the BCA Protein Assay Kit (Pierce Biotechnology Inc., Rockford, IL). Western blot analysis of the whole cell lysates was performed, and a housekeeping gene product $\beta$-actin served as a control for equal loading. Samples were resuspended in a loading buffer (200 mM Tris, pH 6.8, 8\% sodium dodecylsulfate, $0.4 \%$ bromophenol blue, $40 \%$ glycerol, $400 \mathrm{mM}$ dithiothreitol) and heated 5 minutes at $90^{\circ} \mathrm{C}$. Denatured proteins ( $\left.80 \mu \mathrm{g} / \mathrm{sample}\right)$ were separated on $12 \%$ denaturing polyacrylamide gels (sodium dodecyl sulfate-polyacrylamide gel electrophoresis) and transferred to nitrocellulose membranes (Hybond C, Amersham Biosciences, Buckinghamshire, England). Membranes were blocked for 1 hour with a $5 \%(\mathrm{w} / \mathrm{v})$ nonfat dry milk solution containing $10 \mathrm{mM}$ Tris-Cl, $\mathrm{pH} 7.5,140 \mathrm{mM} \mathrm{NaCl}$, and $0.1 \%$ Tween 20 (TBS-T) before their incubation for 1 hour with a primary antibody against Bax or $\beta$-actin (Sigma), diluted 1:2500 with 2.5\% nonfat dry milk in TBS-T. After washing, the membranes were incubated with a species-appropriate horseradish peroxidase-linked immunoglobulin-G antibody (Amersham Biosciences), diluted 1:4000 in TBS-T, and the labeled proteins were detected using enhanced chemiluminescence reagents as described by the manufacturer (Amersham Biosciences). The band intensity was quantitated using the software Image J (National Institutes of Health, Bethesda, MD).

\section{Statistical analysis}

Statistical analysis was performed using the Statistical Package for the Social Sciences Software version 12.0 (SPSS Inc., Chicago, IL). The chi-square and Fisher exact tests were used to compare the frequencies of genotypes and the clinical characteristics between the groups. Odds ratios and their 95\% confidence intervals were also calculated. The observed genotype frequencies were compared with the expected Hardy-Weinberg distributions by chi-square analysis. Neutrophil apoptotic values between genotypes and allelic groups were compared with an analysis of variance test and presented as the mean \pm standard deviation. All reported $P$ values were two-sided. A $P$ value less than .05 was considered statistically significant.

\section{RESULTS}

\section{Frequency of the G(-248)A bax promoter polymorphisms in osteomyelitis}

To determine the $\mathrm{G}(-248) \mathrm{A}$ polymorphism in the bax promoter gene, genomic DNA from patients with OM was amplified and PCR products were subsequently digested with the enzyme Aci I. Restriction fragment length polymorphism analysis of the excised sections of the gene was then performed. The $\mathrm{G}(-248)$ A polymorphism in the bax promoter was in HardyWeinberg equilibrium among patients with $\mathrm{OM}$ and controls. Individuals with the $\mathrm{G}(-248) \mathrm{A}$ bax promoter polymorphism A allele were significantly more frequent among the 80 patients with OM than in the 220 healthy controls ( $18.1 \%$ vs. $10.6 \%$, $\chi^{2}=4.84$, odds ratio $1.81,95 \%$ confidence interval 1.0-3.07, 
Table 1

Genotypic and allelic frequencies of bax promoter G(-248)A polymorphism in patients with osteomyelitis and controls

\begin{tabular}{lrrrrr}
\hline & \multicolumn{3}{c}{ Genotypic frequencies } & & \multicolumn{2}{c}{ Allelic frequencies } \\
\cline { 2 - 4 } & \multicolumn{1}{c}{ GG } & GA & AA & G \\
\hline Patients with OM $(n=80)$ & $53(66.2 \%)$ & $25(31.3 \%)$ & $2^{a}(2.5 \%)$ & $131(81.9 \%)$ & $29^{b}(18.1 \%)$ \\
Controls $(n=220)$ & $173(78.6 \%)$ & $46(20.9 \%)$ & $1(0.5 \%)$ & $392(89.4 \%)$ & $48(10.6 \%)$ \\
\hline
\end{tabular}

OM, osteomyelitis.

${ }^{a} P=.17, \chi^{2}=2.48$, odds ratio $=5.62,95 \%$ confidence interval $=0.39-158.68$ when comparing the genotypic frequencies between patients with OM and controls. ${ }^{b} P=.028, \chi^{2}=4.84$, odds ratio $=1.81,95 \%$ confidence interval $=1.06-3.07$ when comparing the allelic frequencies between patients with $\mathrm{OM}$ and controls.

$P=.028$ by the Yates correction). However, although homozygotes for the $\mathrm{G}(-248) \mathrm{A}$ bax promoter polymorphism (AA genotype) were more frequent among the 80 patients with $\mathrm{OM}$ than in the 220 healthy controls, the difference between groups was not statistically significant $(2 / 80[2.5 \%]$ vs. $1 / 220[0.5 \%]$, $P=.17)$ (Table 1).

\section{Effect of the G(-248)A bax promoter polymorphism on the cause and pathogenesis of osteomyelitis}

A possible correlation between the bax polymorphism and the clinical presentation of the patients with OM was studied. There were no differences in the age, gender, source of infection (posttraumatic or hematogenous), microorganisms found (S. aureus vs. Gram-negative bacteria), or evolution (chronic or acute) between carriers and noncarriers of the A allele of the bax polymorphism (Table 2). Finally, there were no significant differences in different pathogenic predisposing factors to $\mathrm{OM}$ among the carriers of the different $\mathrm{G}(-248) \mathrm{A}$ bax promoter polymorphism genotypes (Table 3). Therefore, the predisposition to OM is due to the presence of this bax polymorphism.

\section{Neutrophil apoptosis}

To determine whether the G(-248)A bax promoter polymorphism was associated with abnormal lifespan of neutrophils, we examined the spontaneous cell death and apoptosis of peripheral neutrophils after 12 hours of incubation in Ham's medium. Cell death and apoptosis of neutrophils from patients with $\mathrm{OM}$ and

Table 2

Clinical characteristics of patients with osteomyelitis with different genotypes of bax promoter $\mathrm{G}(-248)$ A polymorphism

\begin{tabular}{lccc}
\hline $\begin{array}{l}\text { Bax G(-248)A } \\
\text { genotype }\end{array}$ & GG & GA/AA & $P$ value \\
\hline No. of cases & 53 & 27 & Not applicable \\
Mean age, y & $56.6 \pm 18.6$ & $54.8 \pm 16.6$ & .9 \\
Male/female & $36 / 17$ & $19 / 8$ & .8 \\
Chronic/acute OM & $14 / 39$ & $11 / 16$ & .2 \\
$\begin{array}{l}\text { Hematogenous/post } \\
\text { traumatic OM }\end{array}$ & $14 / 39$ & $7 / 20$ & .9 \\
$\begin{array}{l}\text { Gram-negative } \\
\quad \text { bacteria/S. aureus }\end{array}$ & $16 / 37$ & $6 / 21$ & .5 \\
$\quad$ OM & & & \\
\hline
\end{tabular}

OM, osteomyelitis.
Table 3

Predisposing factors for osteomyelitis in carriers of the different genotypes of bax promoter $\mathrm{G}(-248)$ A polymorphism

\begin{tabular}{lcccc}
\hline $\begin{array}{l}\text { Bax G(-248) } \\
\text { A genotype }\end{array}$ & $\mathrm{GG}(n=53)$ & $\mathrm{GA}(n=25)$ & $\mathrm{AA}(n=2)$ & $P$ value \\
\hline Paraplegia (\%) & $7 / 53(13.2)$ & $3 / 25(12.0)$ & $0 / 2(0.0)$ & .88 \\
$\begin{array}{l}\text { Peripheral vascular } \\
\quad \text { disease (\%) }\end{array}$ & $3 / 53(5.7)$ & $1 / 25(4.0)$ & $0 / 2(0.0)$ & .75 \\
Cavus foot (\%) & $2 / 53(3.8)$ & $1 / 25(4.0)$ & $0 / 2(0.0)$ & .96 \\
Diabetes & $7 / 53(13.2)$ & $1 / 25(4.0)$ & $0 / 2(0.0)$ & .21 \\
Other factors ${ }^{a}(\%)$ & $3 / 53(5.7)$ & $4 / 25(16.0)$ & $0 / 2(0.0)$ & .13 \\
Total factors $(\%)^{2}$ & $21 / 53(39.6)$ & $10 / 25(40.0)$ & $0 / 2(0.0)$ & .97 \\
\hline
\end{tabular}

NS, not significant.

${ }^{a}$ Sensitive polyneuropathy, Ewing sarcoma, prostate cancer, cerebrovascular stroke, liver cirrhosis, morbid obesity, hemophilia.

carriers and noncarriers of the A allele were significantly decreased in relation to controls, as we previously reported ${ }^{39}$ Cell death rate for the AA group differs from that in the heterozygous GA $(15.2 \% \pm$ $5.4 \%$ vs. $26.8 \% \pm 18.2 \%, P=.066$ ) and the wild-type GG groups $(15.2 \% \pm 5.4 \%$ vs. $50.2 \% \pm 26.5 \%, P=.107)$ by PI staining (Fig. $2 \mathrm{~A})$. Patients with $\mathrm{OM}$ who were carriers of the A mutated allele had a significantly lower cell death rate of their neutrophils compared with patients who were carriers of the wild-type $\mathrm{G}$ allele $(24.2 \% \pm 16.6 \%$ vs. $50.2 \% \pm 26.5 \%, P=.026)$ (Fig. $2 \mathrm{~B})$. When binding of Annexin $\mathrm{V}$ was used as a marker for apoptotic cells, ${ }^{42}$ patients with $\mathrm{OM}$ who were carriers of the mutated A allele of this G (-248) A bax promoter polymorphism showed a significantly lower apoptotic rate of their neutrophils compared with patients with the wild-type GG genotype $(33.3 \% \pm 16.7 \%$ vs. $43.1 \% \pm$ $3.1 \%, P=.036$ ) (Fig. 2C).

\section{Bax protein expression in freshly isolated human neutrophils}

To determine whether the G(-248)A bax promoter polymorphism was associated with abnormal Bax expression, neutrophil lysates of patients with OM with different bax genotypes were assessed by Western blotting with a commercially available antibody to Bax. Patients with the AA genotype showed a significantly lower expression of Bax compared with those with the GA and GG genotypes (46.7 \pm 25.1 vs. $79.2 \pm$ 24.3 optical density arbitrary units, $P=.038$ ) (Fig. 3). 


\section{Propidium iodide staining}

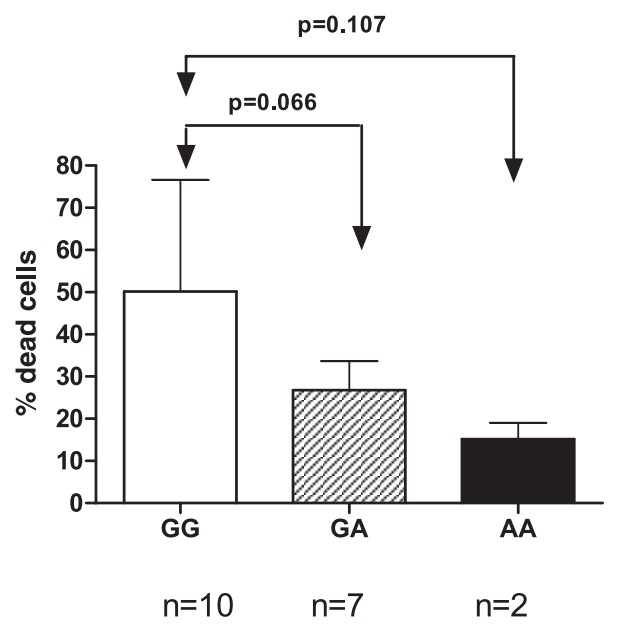

G(-248)A Bax polymorphism genotypes

A

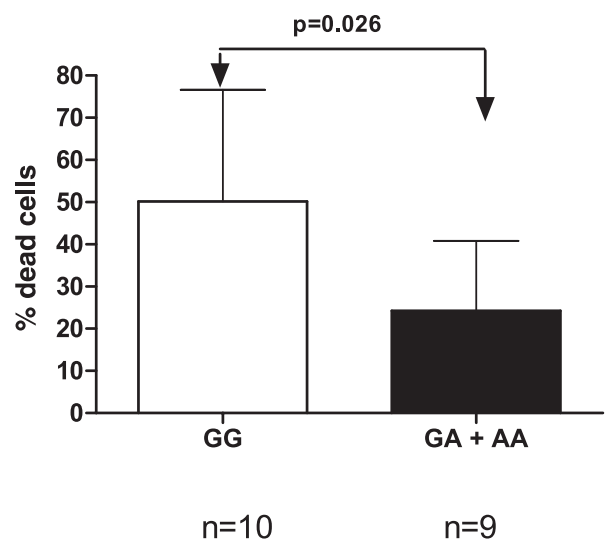

G(-248)A Bax polymorphism genotypes

B

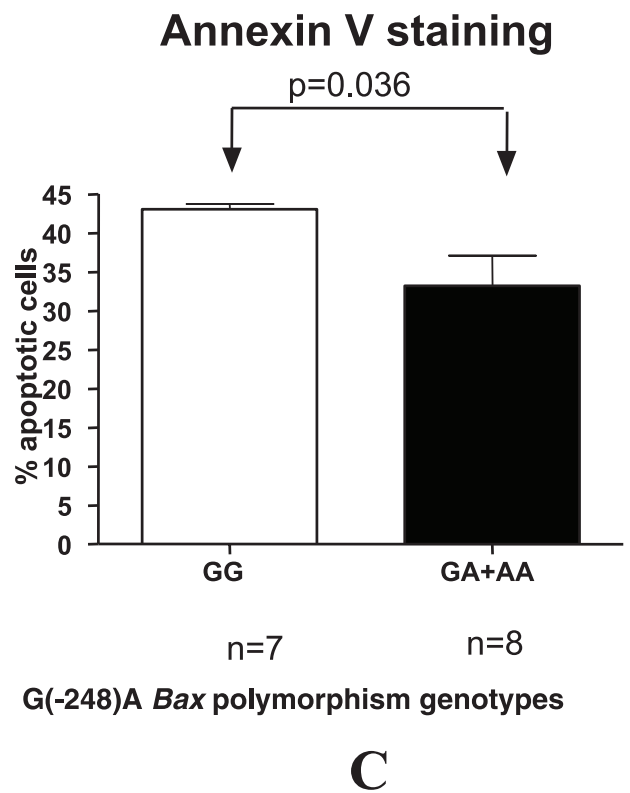

Fig. 2. Cell death and apoptosis of neutrophils of patients with OM with different bax $\mathrm{G}(-248) \mathrm{A}$ polymorphism genotypes. Neutrophils $\left(0.5-1 \times 10^{7}\right)$ of patients with $\mathrm{OM}$ were incubated at $37^{\circ} \mathrm{C}$ in Ham's medium, and cell death (A and B) and apoptosis (C) were measured after 12 hours with PI/annexin V-fluorescein isothiocyanate staining and flow cytometry. Results represent the mean \pm standard deviation of the patients.

\section{DISCUSSION}

Bacterial OM causes substantial morbidity worldwide, despite improvements in medical and surgical management. The clinical course and outcome of this bone infection differs from patient to patient even among those of the same age, gender, microorganism, bone involved, and source of infection. For these reasons, perhaps the genetic background of patients with OM may be responsible for this variability that could signify disease susceptibility and/or poor clinical outcome. To date, several gene polymorphisms have been reported as predisposing one to develop OM. ${ }^{2-4}$ The present work brings additional information to this subject by finding that a polymorphism in the bax promoter $\mathrm{G}(-248) \mathrm{A}$ was more frequent among patients with OM (18.1\%) compared with controls (10.6\%). Our findings regarding the allelic frequency of this polymorphism are in agreement with previous reports. Thus, the A allele frequency of the G(-248)A bax promoter polymorphism found in our control white population of 220 Blood Bank donors was similar to that reported by Starcynski et al. ${ }^{43}$ in 135 British white volunteers $(8.0 \%)$, and it was a little higher than that reported by Saxena et al. ${ }^{18}$ in 25 healthy Canadians (3\%), although they did not report their racial background. Unlike 


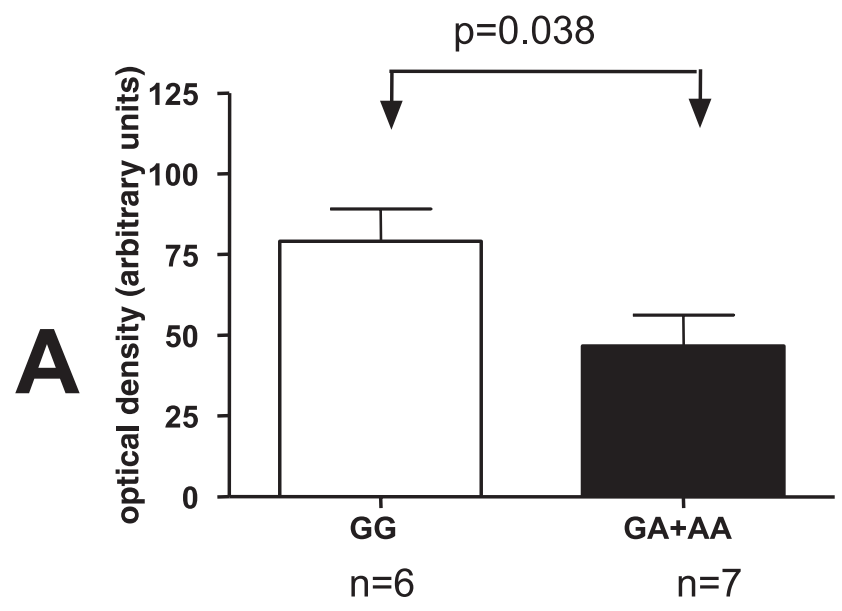

G(-248)A Bax polymorphism genotypes

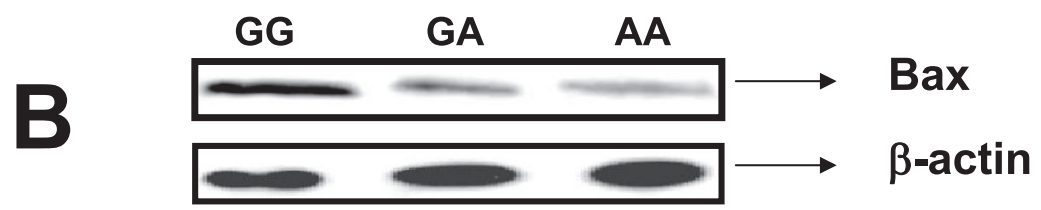

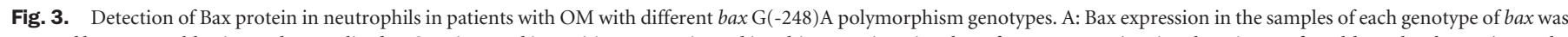

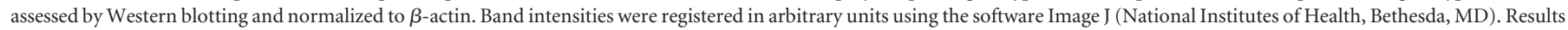
represent the mean \pm standard deviation of the patients. B: Results of the Western blot assay of a representative sample of each genotype. $\beta$-actin is used as a loading control.

other cytokine polymorphisms, such as the IL- $1 \alpha(-889)$ associated with a younger age at diagnosis of $\mathrm{OM},{ }^{2}$ or the TLR4 (Asp299Gly) associated with Gram-negative bacteria and hematogenous OM, ${ }^{4}$ carriers of the A allele of the G(-248)A bax promoter polymorphism did not show differences in their age, gender, source of infection, microorganism involved, or condition predisposing to $\mathrm{OM}$ when compared with noncarriers of the allele.

Bax is a death-promoting protein shown to be a tumor suppressor that stimulates cellular apoptosis in vivo. ${ }^{44,45}$ The bax gene is located on chromosome 19 and consists of six exons and a promotor region with four p53 binding sites. ${ }^{46}$ Sequence variations in the promotor region and coding sequence can abolish its proapoptotic function. ${ }^{17}$ The promoter region with G-to-A SNP consists of potential binding sites for c-Myb, and single nucleotide substitutions in this region may affect c-myb-induced transcriptional activation. ${ }^{18,47}$ The G(-248)A bax promoter polymorphism is associated with disease progression, treatment resistance, and shorter survival in patients with chronic lymphocytic leukemia and with decreased cell Bax expression. ${ }^{18,43,47}$ It is known that changes in the $5^{\prime}$-untranslated region sequence can inhibit initiation of translation and that the altered expression of Bax protein more likely involves a posttranscriptional mechanism. ${ }^{18}$ Other genetic variants in the bax gene have been found in B-cell lymphomas and several cell lines of human hematopoietic malignancies. ${ }^{16,48,49}$ However, SNPs of the bax gene are rare, and the G(-248)A promoter SNP, studied in the present work, is the most impor- tant among them. Ours is the first report of an association between a bax gene SNP and an infection, OM. We also found that the $\mathrm{G}(-248) \mathrm{A}$ bax promoter polymorphism in patients with $\mathrm{OM}$ was associated with an increased survival of their neutrophils. This bax polymorphism was also associated with reduced Bax protein expression by neutrophils. Therefore, it seems likely that this polymorphism is responsible at least in part for the dysregulation of the apoptotic cascade that we observed in the neutrophils of patients with OM. It could be speculated that neutrophils of carriers of the A allele, which have a blunted cellular response to p53 activation and a low constitutive expression of Bax, ${ }^{43,49}$ may have an increased response to IL-6 and other cytokines found at increased levels in serum of patients with OM that delays neutrophils apoptosis. IL-6 enhances the expression of the antiapoptotic proteins Mcl-1, A1, and Bcl- $\mathrm{X}_{1}$ and inhibits constitutive Bax expression, therefore enhancing the antiapoptotic effect of A allele of the G(-248)A bax promoter polymorphism on peripheral neutrophils of patients with OM. ${ }^{8,33,38,39}$ Neutrophils with an extended lifespan in the infected bone may help to perpetuate the bone infection by release of their proteolytic enzymes.

Finally, we cannot rule out that this G(-248)A bax promoter polymorphism could be in linkage disequilibrium with an unidentified variant responsible for the observed effect on neutrophil lifespan and Bax expression.

More research is needed to clarify in depth how this antiapoptotic effect of the G(-248)A bax promoter polymorphism may affect the susceptibility to develop OM. 


\section{ACKNOWLEDGMENTS}

These results were presented in part at the 46th Intersciences Conference on Antimicrobial Agents and Chemotherapy, San Francisco, California, September 26 to 30, 2006, abstract B-1047/4. This study was supported by the research grants IR-00-519-59 and MB-02-519-1 from Oviedo University, Spain; FICYT grant PB02019; and Fondo de Investigaciones Sanitarias grant PI030282 (all given to Dr. Victor Asensi).

\section{References}

1. Lew DP, Waldvogel FA. Osteomyelitis. Lancet 2004;364:369-379.

2. Asensi V, Alvarez V, Valle E, Meana A, et al. An IL-1 $\alpha(-889)$ promoter polymorphism is a risk factor for osteomyelitis. Am J Med Gen 2003;119A:132-136.

3. Asensi V, Montes AH, Valle E, Ocaña MG, et al. The NOS3 (27-bp repeat, intron 4) polymorphism is associated with susceptibility to osteomyelitis. Nitric Oxide 2007; 16:44-53.

4. Montes AH, Asensi V, Alvarez V, Valle E, et al. The Toll-like receptor 4 (Asp299Gly) polymorphism is a risk factor for Gram-negative and haematogenous osteomyelitis. Clin Exp Immunol 2006;143:404-413.

5. Liles WC, Klebanoff SJ. Regulation of apoptosis in neutrophils. Fast track to death ? J Immunol 1995; 155:3289-3291.

6. Savill J. Apoptosis in resolution of inflammation. J Leukoc Biol 1997;61:375-380.

7. Savill J, Dransfield I, Gregory C, Haslett C. A blast from the past: clearance of apoptotic cells regulates immune responses. Nat Rev Immunol 2002;2:965-975.

8. Akgul C, Moulding DA, Edwards SW. Molecular control of neutrophils apoptosis. FEBS Lett 2001;487:318-332.

9. Edwards SW, Derouet M, Howse M, Moots RJ. Regulation of neutrophil apoptosis by Mcl-1. Biochem Soc Trans 2004;32:489-492.

10. Weinmann P, Gaehtgens P, Walzog B. Bcl-X1 and Bax-mediated regulation of apoptosis of human neutrophils via caspase-3. Blood 1999;93:3106-3115.

11. Petros AM, Olejniczak ET, Fesik SW. Structural biology of the Bcl-2 family of proteins. Biochim Biophys Acta 2004;1644:83-94.

12. van Delft MF, Huang DC. How the Bcl-2 family of proteins interact to regulate apoptosis. Cell Res 2006;16:203-213.

13. Zha H, Aime-Sempe C, Sato T, Reed JC. Proapoptotic protein Bax heterodimerizes with Bcl-2 and homodimerizes with Bax via a novel domain (BH3) distinct from BH1 and BH2. J Biol Chem 1996;271:7440-7444.

14. Kitada S, Andersen J, Akar S, Zapata JM, et al. Expression of apoptosis-regulating proteins in chronic lymphocytic leukemia: correlations with "in vitro" and "in vivo" chemoresponses. Blood 1998;91:3379-3389.

15. Pepper C, Hoy T, Bentley P. Elevated Bcl-2/Bax are a consistent feature of apoptosis resistance in B-cell chronic lymphocytic leukaemia and are correlated with in vivo chemoresistance. Leuk Lymphoma 1998;28:355-361.

16. Meijerink JP, Mensink EJ, Wang K, Sedlak TW, et al. Hematopoietic malignancies demonstrate loss-of-function mutations of BAX. Blood 1998;91:2991-2997.

17. Rampino N, Yamamoto H, Ionov Y, Li Y, et al. Somatic frameshift mutations in the BAX gene in colon cancers of the microsatellite mutator phenotype. Science 1997; 275:967-969.

18. Saxena A, Moshynska O, Sankaran K, Viswanathan S, et al. Association of a novel single nucleotide polymorphism, G(-248)A, in the 5'-UTR of BAX gene in chronic lymphocytic leukemia with disease progression and treatment resistance. Cancer Lett 2002;187:199-205.

19. Moshynska O, Sankaran K, Saxena A. Molecular detection of the G(-248)A BAX promoter nucleotide change in B cell chronic lymphocytic leukaemia. Mol Pathol 2003;56:205-209.

20. Abraham E. Neutrophils and acute lung injury. Crit Care Med 2003;31:S195-S199.

21. Melley DD, Evans TW, Quinlan GJ. Redox regulation of neutrophil apoptosis and the systemic inflammatory response syndrome. Clin Sci (Lond) 2005;108:413-424.

22. Vinten-Johansen J. Involvement of neutrophils in the pathogenesis of lethal myocardial reperfusion injury. Cardiovasc Res 2004;61:481-497.

23. Xing Z, Gauldie J, Cox G, Baumann H, et al. IL-6 is an antiinflammatory cytokine required for controlling local or systemic acute inflammatory responses. J Clin Invest 1998;101:311-320.

24. Evans CA, Jellis J, Hughes SP, Remick DG, et al. Tumor necrosis factor- $\alpha$, interleukin 6 , and interleukin- 8 secretion and the acute-phase response in patients with bacterial and tuberculous osteomyelitis. J Infect Dis 1998;177:1582-1587.
25. Klosterhalfen B, Peters KM, Töns C, Hauptmann S, et al. Local and systemic inflammatory mediators release in patients with acute and chronic posttraumatic osteomyelitis. J Trauma 1996;40:372-378.

26. Bost KL, Raup WK, Nicholson NC, Bento JL, et al. Staphylococcus aureus infection of mouse or human osteoblasts induces high levels of interleukin-6 and interleukin-12 production. J Infect Dis 1999;150:1912-1920.

27. Yoon KS, Fitzgerald RH, Sud S, Song Z, et al. Experimental acute hematogenous osteomyelitis in mice. II. Influence of Staphylococcus aureus infection on T-cell immunity. J Orthop Res 1999;17:382-391.

28. Dibbert B, Weber M, Nikolaizik WH, Vogt P, et al. Cytokine-mediated Bax deficiency and consequent delayed neutrophil apoptosis. A general mechanism to accumulate effector cells in inflammation. Proc Natl Acad Sci U S A 1999;96:1333013335.

29. Fanning NF, Kell MR, Shorten GD, Kirwan WO, et al. Circulating granulocyte colony-stimulating factor in plasma of patients with the systemic inflammatory response syndrome delays neutrophil apoptosis through inhibition of spontaneous reactive oxygen species generation. Shock 1999;11:167-174.

30. Matsuda T, Saito H, Fukatsu K, Han I, et al. Cytokine-modulated inhibition of neutrophil apoptosis at local site augments exudative neutrophil functions and reflects inflammatory response after surgery. Surgery 2001;129:76-85.

31. Murray J, Barbara JA, Dunkley SA, Lopez AF, et al. Regulation of neutrophil apoptosis by tumor necrosis factor- $\alpha$ : requirement for TNFR55 and TNFR75 for induction of apoptosis in vitro. Blood 1997;90:2772-2783.

32. Daffern DJ, Jageles MA, Hugli TE. Multiple epithelial cell-derived factors enhance neutrophil survival. Regulation by glucocorticoids and tumor-necrosis factor-alpha. Am J Resp Cell Mol Biol 1999;21:259-267.

33. Biffl WL, Moore EE, Moore FA, Barnett CC. Interleukin-6 suppression of neutrophil apoptosis is neutrophil concentration dependent. J Leukoc Biol 1995;58:582584.

34. Biffl WL, Moore E, Moore FA, Barnett CC, et al. Interleukin-6 delays neutrophil apoptosis. Arch Surg 1996;131:24-30.

35. Fanning NF, Porter J, Shorten GD, Kirwan WO, et al. Inhibition of neutrophil apoptosis after elective surgery. Surgery 1999;126:527-534.

36. Kaplanski G, Marin V, Montero-Julina F, Mantovani A, et al. IL-6: a regulator of the transition from neutrophil to monocyte recruitment during inflammation. Trends Immunol 2003;24:25-30.

37. Weinmann P, Scharffetter-Kochanek K, Bardley-Forlow S, Peters T, et al. A role for apoptosis in the control of neutrophil homeostasis in the circulation: insights from CD18-deficient mice. Blood 2003;101:739-746.

38. Ottonello L, Frumento G, Arduino N, Bertolotto M, et al. Differential regulation of spontaneous and immune complex-induced neutrophil apoptosis by proinflammatory cytokines. Role of oxidants, Bax and caspase-3. J Leukoc Biol 2002;72:125-132.

39. Asensi V, Valle E, Meana A, Fierer J, et al. In vivo interleukin-6 protects neutrophils from apoptosis in osteomyelitis. Infect Immun 2004;72:3823-3828.

40. Nicoletti I, Migliorati G, Oagliacci MC, Grignani F, et al. Rapid and simple method for measuring thymocyte apoptosis by propidium iodine staining and flow cytometry. J Immunol Meth 1991;139:271-279.

41. Miller SA, Dykes DD, Polesky HF. A simple salting out procedure for extracting DNA from human nucleated cells. Nucleic Acids Res 1988;16:1215-1222.

42. Homburg CH, de Haas M, von dem Borne AE, Verhoeven AJ, et al. Human neutrophils lose their surface Fc gamma RIII and acquire Annexin V binding sites during apoptosis in vitro. Blood 1995;85:532-540.

43. Starcynski J, Pepper C, Pratt G, Hooper L, et al. Common polymorphism G(-248) A in the promoter region of the bax gene results in significantly shorter survival in patients with chronic lymphocytic leukemia once treatment is initiated. J Clin Oncol 2006;23:1514-1521.

44. Bellosillo B, Villamor N, Lopez-Guillermo A, Marce S, et al. Spontaneous and druginduced apoptosis is mediated by conformational changes of Bax and Bak in B-cell chronic lymphocytic leukemia. Blood 2002;100:1810-1816.

45. Zhang L, Yu J, Park BH, Kinzler KW, et al. Role of BAX in the apoptotic response to anticancer agents. Science 2000;290:989-992.

46. Miyashita T, Reed JC. Tumor suppressor p53 is a direct transcriptional activator of the human bax gene. Cell 1995;80:293-299.

47. Luescher B, Eisenman RN. New light on Myc and Myb. Part II. Myb. Genes Dev 1990;4:2235-2241.

48. Peng H, Aiello A, Packham G, Isaacson PG, et al. Infrequent bax gene mutations in B-cell lymphomas. J Pathol 1998;186:378-382.

49. Moshynska O, Moshynskyy I, Misra V, Saxena A. G125A single-nucleotide polymorphism in the human BAX promoter affects gene expression. Oncogene 2005;24: 2042-2049. 